J. Clin. Chem. Clin. Biochem.

Vol. 27, 1989, pp. 807-813

(C) 1989 Walter de Gruyter \& Co. Berlin - New York

\title{
Improved Method for Enzymic Determination of Cholesterol in Lipoproteins Separated by Electrophoresis on Thin Layer Agarose Gels
}

\author{
By J. Aufenanger, P. Haux and R. Kattermann') \\ Institut für Klinische Chemie, Klinikum Mannheim der Universität Heidelberg, Mannheim, F.R.G.
}

(Received April 4/July 24, 1989)

\begin{abstract}
Summary: The cholesterol of lipoproteins, separated electrophoretically on thin layer agarose films, is visualised and quantitated by incubating the gels in an enzymic reagent containing cholesterol esterase and cholesterol dehydrogenase. The individual fractions are quantitated by scanning densitometry. No sample pretreatment is necessary. All major fractions are detected readily. The accuracy of the determination is similar to that of ultracentrifugation. On average, imprecision is $3.1 \%$ for $\beta-, 7.0 \%$ for pre $\beta$-, and $4.8 \%$ for $\alpha$-lipoprotein cholesterol. Concentration and colour development are linear up to $8 \mathrm{mmol} / \mathrm{l}$ cholesterol in a given lipoprotein fraction. The results from the direct enzymic procedure for $\beta$-, pre $\beta$ - and $\alpha$-lipoprotein cholesterol are compared with those from quantitative lipoprotein electrophoresis after precipitation with phosphotungstic acid and bivalent cations and with those from different precipitation methods using dextran sulphate and polyethylene glycol.
\end{abstract}

The new method has several advantages: high specificity; lack of dependence on the actual composition of the lipoproteins; lack of interference from coprecipitated proteins in the gel, e.g. fibrinogen or paraproteins; and insensitivity to lipolysis and high free fatty acid concentrations caused by heparin application or ageing of the specimen (at least for $\alpha$-lipoprotein cholesterol quantitation). In its convenience and simplicity of operation, and the simple calculation of results, the method is similar to standard protein electrophoresis. The proposed method is therefore suggested as a standard method for elucidating lipoprotein disorders.

\section{Introduction}

A series of epidemiological and clinical studies (1-4) has shown the significance of serum lipoprotein fractions in the development of coronary heart disease. This has led to an increased demand for lipoprotein determination and the quantitation of their individual lipid content. A variety of methods has been developed in order to avoid the expensive and time-consuming use of ultracentrifugal procedures. Either selective differential precipitation of lipoproteins $(5-8)$ or quantitative lipoprotein electrophoresis $(9-13)$ have been proposed as methods of choice. The latter

1 On the occasion of the $25^{\text {th }}$ anniversary of the German Society for Clinical Chemistry (cf. Editorial, this J. 27, 529 (1989)) method is based on polyanion precipitation of electrophoretically separated lipoproteins and densitometric measurement of the relative amounts of $\beta$-, pre $\beta$-, and $\alpha$-lipoprotein. The cholesterol content must then be calculated from the protein moieties with empirical factors. The derivation of these factors implies a constant lipoprotein/lipid ratio, a prerequisite not always fullfilled. The precipitation of lipoproteins in agarose gel depends on temperature, incubation time, composition of the lipoproteins themselves and on the composition of the precipitating agent. This leads to distinct differences in the lipid concentration of the separated subfractions $(9,12,14-16)$. In addition, the lipoprotein composition may vary in several diseases e.g. coronary artery disease (17) and 
diseases accompanied by hypertriacylglycerolaemia (18) - e.g. diabetes mellitus, nephrotic syndrome, various forms of renal and liver diseases - or after drug intervention (19), leaving considerable doubt about the specificity and accuracy of these methods.

Several efforts to assess lipoprotein cholesterol directly after gel electrophoresis $(20,21)$ failed because of technical problems, or lack of linearity, or high diffusion rates after staining.

Recently we reported a technique for enzymic determination of cholesterol-containing lipoprotein classes after electrophoretic separation on thick layer agarose gels (22).

In this communication we present a method using thin layer agarose gels which allow a considerable reduction of the electrophoresis and staining time, and convert the procedure into a truly convenient laboratory method.

\section{Materials and Methods}

The enzymic cholesterol reagent was prepared with the following final concentrations/activities:

- Cholesterol esterase (EC 3.1.1.13, from microorganisms), $(0.4 \mathrm{kU} / \mathrm{l})$ and $\operatorname{NAD}(0.5 \mathrm{mmol} / \mathrm{l})$, both from Boehringer Mannheim, Mannheim, FRG.

- Cholesterol dehydrogenase from Nocardia spec. (0.14 kU/1) from Wako Chemicals, Osaka, Japan.

- Phenazine methosulphate, $(0.03 \mathrm{mmol} / \mathrm{l})$ and 4-nitroblue tetrazolium chloride, $(0.16 \mathrm{mmol} / \mathrm{l})$ from Serva, Heidelberg, FRG.

- TRIS-HCl buffer (57 mmol/1), pH 8.0.

- Test kit for the quantitative lipoprotein electrophoresis LIPIDOPHOR ALL IN (Immuno Diagnostica, Vienna, Austria).

- Thin layer gels were prepared on $7 \mathrm{~cm} \times 8 \mathrm{~cm}$ gel bond foils (Serva, Heidelberg, FRG) using $1 \mathrm{~g} / \mathrm{l}$ agarose (standard EEO, Serva, Heidelberg, FRG) in $4 \mathrm{ml}$ barbital-glycine buffer ( $50 \mathrm{mmol} / \mathrm{l}, \mathrm{pH} 8.6)$.

- Testkits for precipitation of LDL and HDL (QUANTOLIP LDL Cholesterol and QUANTOLIP HDL Cholesterol, both Immuno, Vienna, Austria).

- All other chemicals used were analytical grade.

\section{Control material}

Human pooled serum and a commercially available control serum (Lipidophor R, Immuno Diagnostica, Austria, Vienna) were used in the precision studies and for the determination of linearity and recovery.

\section{Patients}

Blood specimens from fasting patients were collected from the antecubital vein and allowed to clot at room temperature. Most patients had high cholesterol and/or high triacylglycerol con- centrations but they were not preselected according to the Fredrickson classification. Specimens from heparinized patients were excluded. The lipoproteins were separated within $4 \mathrm{~h}$ after sample collection.

\section{Lipoprotein separation by electrophoresis}

\section{Method I: Enzymic determination of lipoprotein cholesterol}

The sera $($ ca $5 \mu \mathrm{l})$ were applied in dúplicate to the thin layer gel via a foil slit, and allowed to diffuse for 10 minutes. The electrophoresis was carried out at $10 \mathrm{~V} / \mathrm{cm}$ for 35 minutes. The tank buffer was barbital-glycine, $50 \mathrm{mmol} / \mathrm{l}, \mathrm{pH}$ 8.6.

The entire gel foils were incubated in the enzymic cholesterol reagent as described above while gently agitating for 2 hours at room temperature or one hour at $37^{\circ} \mathrm{C} \mathrm{(22).} \mathrm{After} \mathrm{incuba-}$ tion, the gel foils were washed in $1 \%$ acetic acid for $15 \mathrm{~min}$ to remove the excess phenazine methosulphate and nitrotetrazolinum blue and dried with forced air. The relative amounts of cholesterol in the purple bands produced by the enzymic method were determined by scanning at $570 \mathrm{~nm}$, and the absolute quantity in each band was derived from its relative content and the known value for total serum cholesterol.

\section{Method II: Precipitation of the lipoproteins (23)}

The method was performed as recommended by the manufacturer (Immuno AG, Vienna, Austria). The lipoprotein cholesterol was calculated using the empirical equation of Wieland \& Seidel $(9,23)$.

One technically delicate step is the neccessity to premix the serum with liquefied agarose, to apply this mixture to the wells free of air bubbles, and to subsequently seal them with agarose. Other drawbacks are the extended electrophoresis time of $\mathbf{8 0}$ minutes, and the total precipitation time of 3 hours.

\section{Lipoprotein separation by ultracentrifugation}

The lipoproteins were separated into very low density lipoproteins (VLDL), low density lipoproteins (LDL) and high density lipoproteins (HDL) by preparative ultracentrifugation essentially as described by Neubeck et al. (9). The ultracentrifugation was performed for $22 \mathrm{~h}$ for VLDL and LDL, and $48 \mathrm{~h}$ forr HDL in a Beckman $\mathrm{L} 5.50$ ultracentrifuge using a $50 \mathrm{Ti}$ rotor at $11000 \mathrm{~g}$. After centrifugation the lipoprotein fractions were thoroughly washed on a molecular membrane filter $\left(M_{\mathrm{r}} 30000\right)$ and stabilized in an albumin solution $(50 \mathrm{~g} / \mathrm{l})$, followed by determination of cholesterol and triacylglycerols with a commercially available test combination from Boehringer Mannheim, Mannheim, FRG $(24,25)$. The purity of the isolated lipoproteins was tested by electrophoresis. For recovery experiments, aliquots of lipoproteins with known cholesterol content were subjected to lipoprotein electrophoresis and detected by the enzymic procedure.

\section{Statistical methods}

The methods were compared according to Passing \& Bablok and the correlation was analysed by Kendall's $\tau$-test $(26,27)$.

\section{Results}

The most effective staining was achieved by gently agitating the gel foil in the enzymic cholesterol reagent. The kinetics of the colour development in the lipoprotein fractions indicated that the end-point for 
the reaction was reached within one hour at room temperature, even for samples with cholesterol concentrations of $15 \mathrm{mmol} / 1$ (22). The colour of the formazan compound faded very gradually, but we saw no alteration in the quantitative distribution of the bands after storage for 3 days in the cold. No diffusion of the bands was observed. The background staining increased noticeably if the gel was not incubated in the dark. The excess of the reagent could be washed out with dilute acetic acid. Thereafter the gels could be dried and stored. Under dry and dark conditions the banding remained stable for at least one year, so that the foil is suitable as a permanent record.

\section{Linearity}

To establish concentration limits, a patient's serum with high total cholesterol was run in serial dilutions. In addition, we used purified lipoprotein fractions from the ultracentrifugation, with known cholesterol contents. Each specimen was electrophoresed twice and scanned by densitometry.

Figure 1 illustrates the results. The data are presented as lipoprotein cholesterol concentration vs. densitometric area equivalent. Linearity was demonstrated up to $8 \mathrm{mmol} / \mathrm{l}$, indicating that there is little risk of depleting the reagent. This allows the measurement of low $\alpha$ - as well as elevated $\beta$-lipoprotein cholesterol concentrations with the same procedure.

\section{Precision}

Sera from 3 patients with different total cholesterol and triacylglycerol contents and the control serum

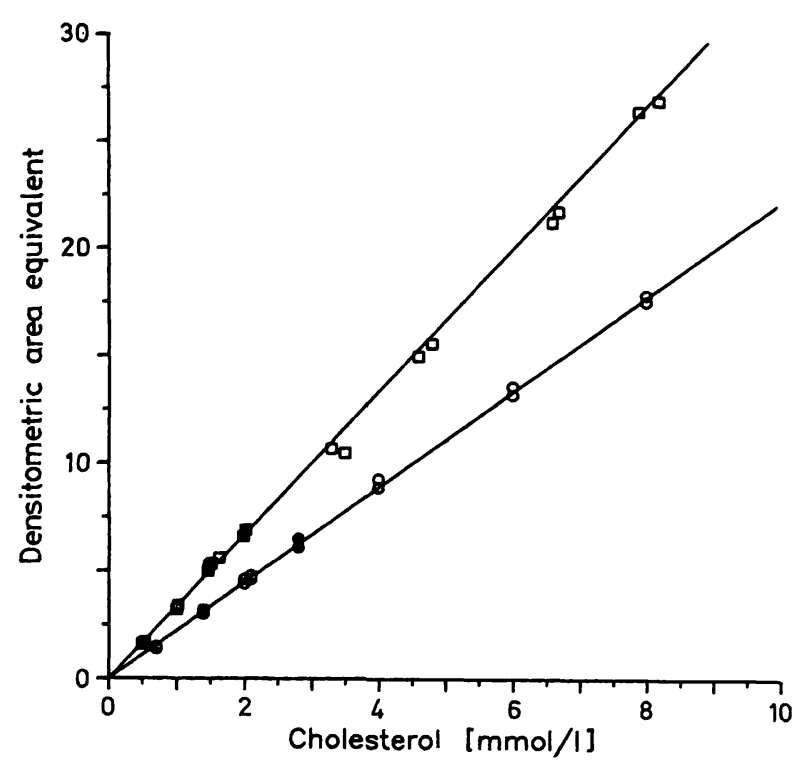

Fig. 1. Linearity: A patient's serum with high cholesterol contents and purified lipoprotein fractions from the ultracentrifugation were serially diluted. Each specimen was electrophoresed twice and scanned by densitometry. The different slopes were caused by different optical amplification factors.

$\square \beta$-lipoprotein-cholesterol (patient)

○ $\beta$-lipoprotein-cholesterol from LDL (ultracentrifugation)

a $\alpha$-lipoprotein-cholesterol (patient)

- $\alpha$-lipoprotein-cholesterol from HDL (ultracentrifugation)

Lipidophor $\mathbf{R}$ were used as samples. The sera were run 12 times. The lipoprotein cholesterol was measured (tab. 1), and the mean and the coefficient of variation were determined.

Tab. 1. Precision studies within rụn.

\begin{tabular}{|c|c|c|c|c|c|c|c|c|}
\hline & Control serum & & Sample I & & Sample II & & Sample III & \\
\hline $\mathbf{N}$ & 12 & & 12 & & 12 & & 12 & \\
\hline $\begin{array}{l}\text { Total cholesterol } \\
(\mathrm{mmol} / \mathrm{l})\end{array}$ & 3.31 & & 4.28 & & 10.35 & & 6.34 & \\
\hline \multirow{2}{*}{$\begin{array}{l}\text { Total triacylglycerols } \\
(\mathrm{mmol} / \mathrm{l})\end{array}$} & $4.80 *$ & & 1.05 & & 1.65 & & 6.12 & \\
\hline & $\begin{array}{l}\overline{\mathrm{x}} \\
(\mathrm{mmol} / \mathrm{l})\end{array}$ & $\begin{array}{l}\text { CV } \\
(\%)\end{array}$ & $\begin{array}{l}\overline{\mathrm{x}} \\
(\mathrm{mmol} / \mathrm{l})\end{array}$ & $\begin{array}{l}\text { CV } \\
(\%)\end{array}$ & $\begin{array}{l}\overline{\mathrm{x}} \\
(\mathrm{mmol} / \mathrm{l}\end{array}$ & $\begin{array}{l}\text { CV } \\
(\%)\end{array}$ & $\begin{array}{l}\overline{\mathrm{x}} \\
(\mathrm{mmol} / \mathrm{l})\end{array}$ & $\begin{array}{l}\text { CV } \\
(\%)\end{array}$ \\
\hline $\begin{array}{l}\beta \text {-Lipoprotein } \\
\text { cholesteról }\end{array}$ & 2.29 & 3.8 & 3.01 & 2.2 & 8.74 & 2.4 & 4.12 & 4.1 \\
\hline $\begin{array}{l}\text { Pre } \beta \text {-Lipoprotein } \\
\text { cholesterol }\end{array}$ & 0.24 & 9.8 & 0.18 & 6.8 & 0.29 & 6.4 & 1.36 & 5.3 \\
\hline $\begin{array}{l}\alpha \text {-Lipoprotein } \\
\text { cholesterol }\end{array}$ & 0.78 & 4.4 & 1.09 & 3.1 & 1.32 & 4.8 & 0.86 & 6.8 \\
\hline
\end{tabular}

\footnotetext{
* Mainly free glycerol
} 


\section{Accuracy}

The accuracy of the method was established by comparing our values with those obtained from well defined lipoprotein fractions. Aliquots of purified LDL-, VLDL- and HDL-fractions with known cholesterol contents were electrophoresed and scanned after enzymic staining. The results are shown in figure $2 a-c$. The recovery of the lipoprotein cholesterol after electrophoretic separation agreed quite well with the directly determined cholesterol contents of the LDL-, VLDL- and HDL-fractions.

\section{Comparison with the LIPIDOPHOR method}

This proposed method was compared with the method of Wieland \& Seidel $(9,10)$, which is generally accepted as being representative for the estimation of cholesterol in lipoproteins $(9-13)$, at least from a normal healthy population. The scatter plots are shown in figure $3 a-c$. The highest agreement was found for the cholesterol content of the $\beta$-lipoprotein fraction $(r=0.984)$. The coefficient of correlation for the $\alpha$-lipoprotein cholesterol fractions was slightly lower $(r=0.954)$. The difference of the intercepts and slopes from the theoretical values are negligible. The comparison of pre $\beta$-lipoprotein cholesterol determinations showed slightly higher values for the enzymic procedure, the coefficient of correlation being 0.947 .

Figure $4 a-c$ presents the comparison of the enzymic staining technique with the direct precipitation techniques in the serum. Both precipitation techniques showed acceptable agreement with the enzymic staining technique. The values for LDL cholesterol were, however, slightly higher, whereas those for HDL cholesterol were about $10 \%$ lower than those measured with the enzymic staining technique. Hence, the correlation of pre $\beta$-lipoprotein cholesterol with the VLDL cholesterol, calculated from the triacylglycerol according to the Friedewald equation, was not acceptable $(r=0.752)$.

Fig. 2a-c. Accuracy: Aliquots of purified LDL-, HDL- and VLDL-fractions with known cholesterol contents ( $x$-axis) were electrophoresed and scanned by densitometry (y-axis) after enzymic staining. Regression procedure was performed according to Passing \& Bablok:

$\mathrm{a}: \mathrm{n}=51, \mathrm{y}=0.97 \mathrm{x}+0.141, \mathrm{r}=0.995$;

b: $\mathrm{n}=23, \mathrm{y}=1.00 \mathrm{x}-0.026, \mathrm{r}=0.979$;

c: $\mathrm{n}=47, \mathrm{y}=1.091 \mathrm{x}-0.126, \mathrm{r}=0.972$.

The confidence belts indicate the range for a single predictive value at $\alpha=0.05$.
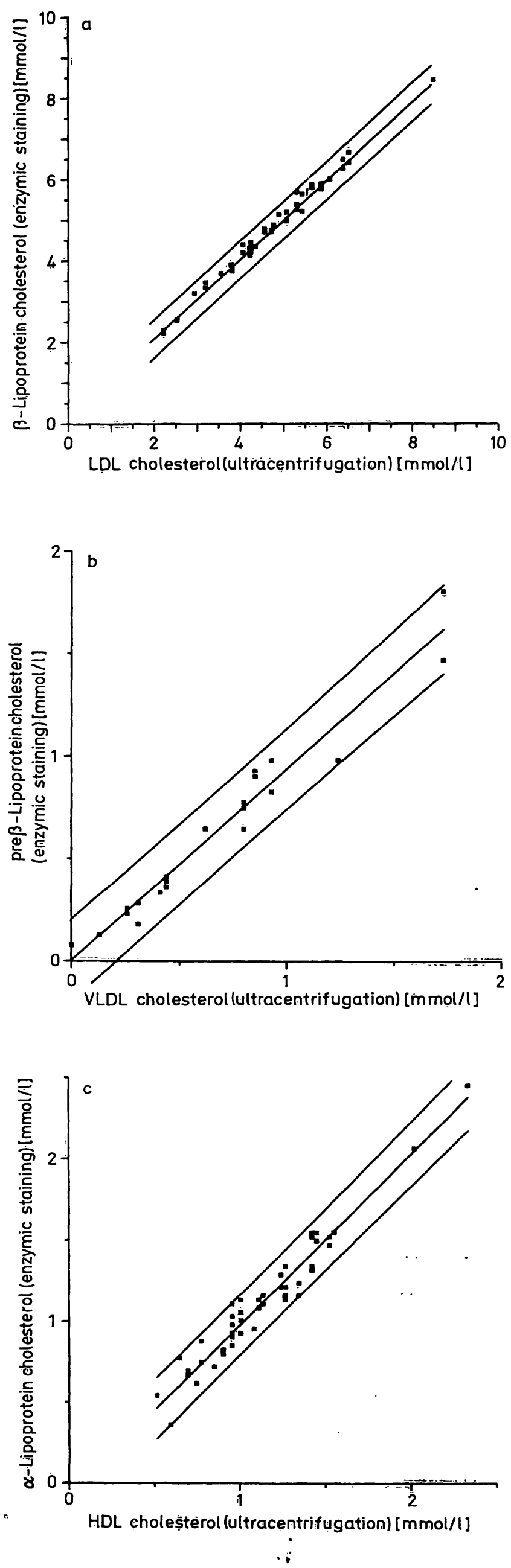

J. Clin. Chem. Clin. Biochem. / Vol. 27, 1989 / No. 10 

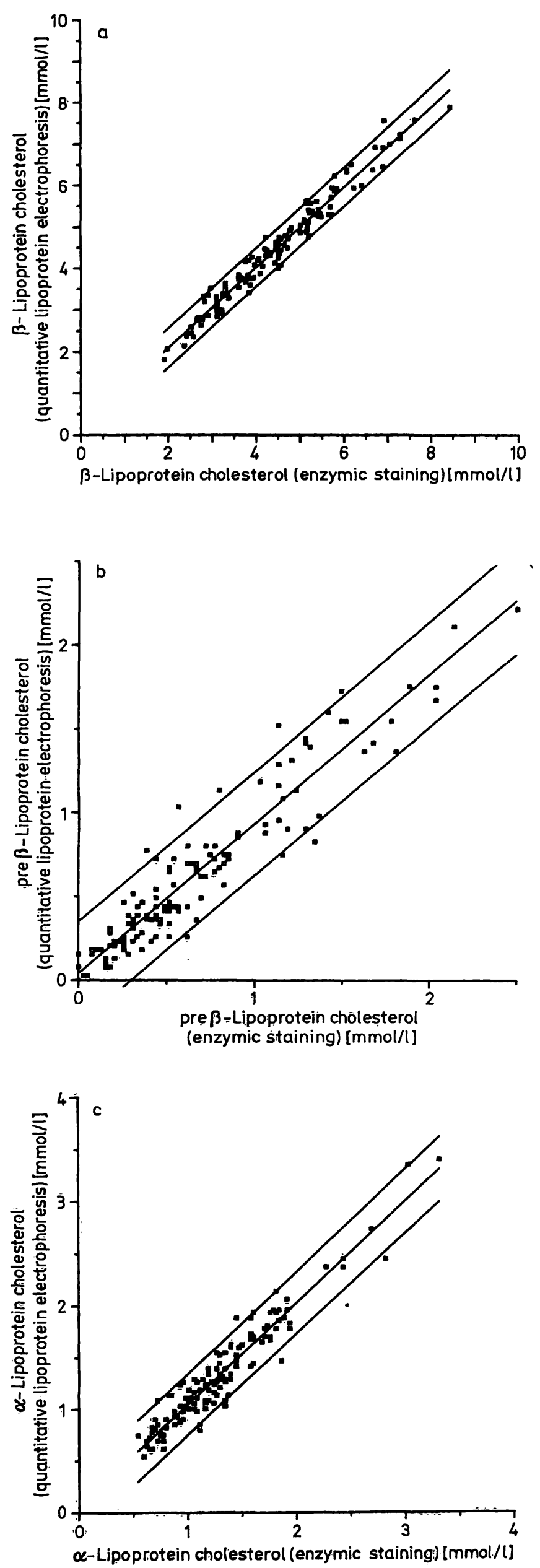

\section{Discussion}

The cholesterol content of the fractions isolated by ultracentrifugation agreed excellently with that determined by electrophoresis combined with the enzymic technique. This confirms the accuracy of the cholesterol determination in the separated bands. The $\beta$ lipoprotein cholesterol values measured by the new technique correlated very well with $\beta$-lipoprotein cholesterol determined with the Lipidophor system. The correlations for pre $\beta$-lipoprotein and $\alpha$-lipoprotein cholesterols were nearly as good. The comparison of the different precipitation techniques also showed satisfactory agreement. On the whole, the three techniques showed good methodical agreement for all lipoprotein fractions.

The interassay precision of the method for normal values approached that reported for quantitative lipoprotein electrophoresis $(15,28)$. At higher values, the CV's slightly exceeded the CV's reported by Wieland \& Seidel for the Lipidophor system using Lipidophor control serum $(8.4 \%, 4.3 \%$, and $5.5 \%$ for pre $\beta$-, $\beta$-, and $\alpha$-lipoprotein, resp.). On the other hand Maerz \& Gross reported CV's in the order of $9-20 \%$ (15).

With respect to linearity, the method is superior to that of $C o b b$ et al. (20). There is no need to dilute samples with high cholesterol contents, which in turn would inevitably lead to a reduced detectability of the $\alpha$-lipoprotein fraction.

All lipoprotein fractions, chylomicrons usually included, contain sufficient cholesterol to be readily detected by this method, except for $L p(a)$-cholesterol which evades correct quantitation because it comigrates with VLDL lipoproteins in the pre $\beta$-band. An implausibly high pre $\beta$-lipoprotein cholesterol compared with the triacylglycerol content may indicate the presence of $L p(a)$.

Fig. 3a-c. Quantitation of lipoprotein cholesterol after electrophoretic separation. Comparison of the enzymic procedure and the so-called quantitative lipoprotein electrophoresis after phosphotungstic acid/ $\mathrm{MgCl}_{2}$ precipitation. Regression was determined by the geometric method according to Passing \& Bablok:

a: $n=140, y=0.986 x+0.052, r=0.984$

b: $n=140, y=0.943 x+0.005, r=0.947$

c: $n=140, y=1.042 x+0.004, r=0.954$.

The confidence belts indicate the range for a single predictive value at $\alpha=0.05$. 

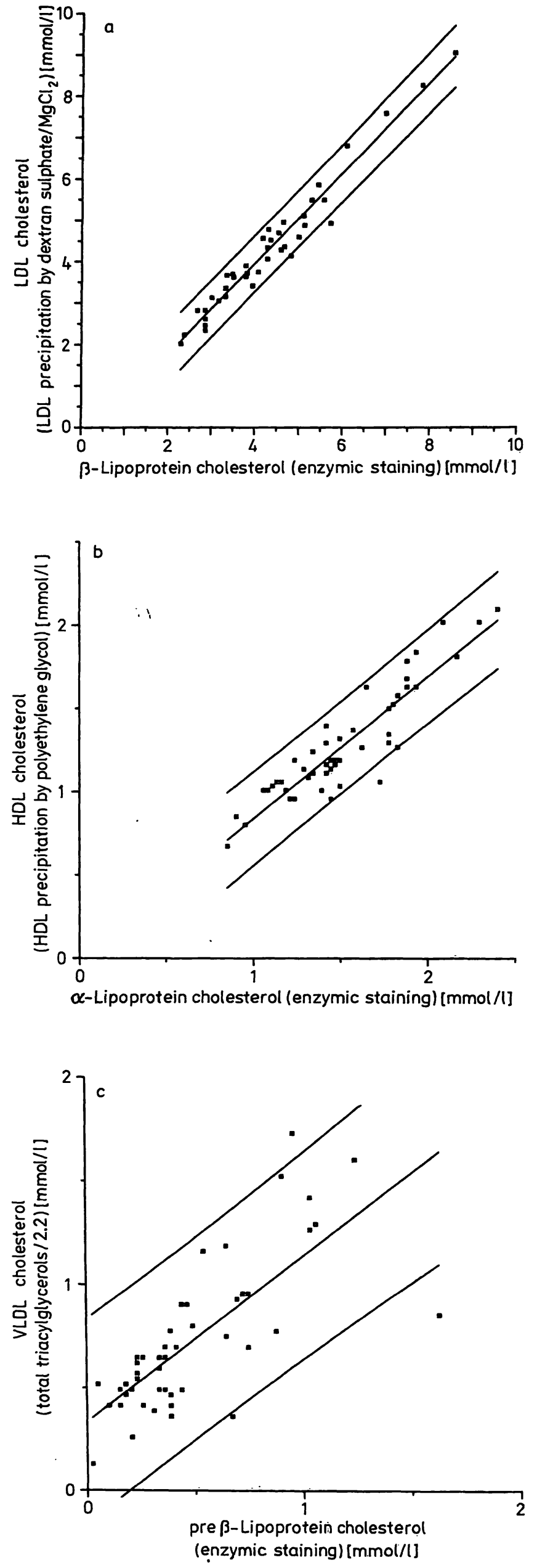

The enzymic technique allows a specific and direct determination of lipoprotein cholesterol, while the quantitation of cholesterol after electrophoresis by the precipitation technique relies on the postulate of a constant lipoprotein composition. The precipitation technique after electrophoresis has additional disadvantages. The results depend upon the temperature (12). The precipitation behaviour of fresh sera is different from that of aged and lipolysed sera (e. g. after heparin therapy). The method is sensitive to coprecipitation of proteins other than lipoproteins. Fibrinogen coprecipitates as well as paraproteins, leading to an overestimation of the lipoproteins. This is particularly crucial for paraproteins in the $\beta$ - and $\alpha_{2}$ region. Atypical lipoproteins must be precipitated with special solutions at a defined $\mathrm{pH}$.

These limitations also hold true for qualitative lipoprotein electrophoresis according to Noble (29). The Friedewald equation (30) for the quantitation of lipoprotein cholesterol is of limited accuracy (31).

It should also be mentioned that lipoprotein- $X$ $(\mathrm{Lp}(\mathrm{X}))$ can be separated and quantified with the same electrophoretic procedure (data not shown here).

The described technique avoids several inconveniences inherent to the Lipidophor system. It is a practical, precise and accurate method for the determination of lipoprotein cholesterol, and it obviates the time-consuming and expensive ultracentrifugation technique.

In summary, the direct enzymic determination of lipoprotein cholesterol after electrophoretic separation has the following advantages:

- High specificity

- Independence of the actual composition of lipoproteins

- Direct qualitative evaluation of the lipoprotein electrophoresis and direct quantitation of the cholesterol content in the individual lipoprotein bands

- Elimination of interference from coprecipitated proteins in the gel, such as fibrinogen or paraproteins

Fig. $4 a-c$. Comparison of the enzymic staining procedure with the direct precipitation method in serum, using dextransulphate $/ \mathrm{MgCl}_{2}$ for $\mathrm{LDL}$ and polyethylene glycol for HDL; VLDL cholesterol was calculated according to the Friedewald equation. Passing \& Bablok:

$\mathrm{a}: \mathrm{n} \equiv 40, \mathrm{y}=1.12 \mathrm{x}+0.48, \dot{\mathrm{r}}=0.98$

b: $\mathrm{n}=50, \mathrm{y}=0.90 \mathrm{x}-0.1, \quad \mathrm{r}=0.913$;

c: $\mathrm{n}=48, \mathrm{y}=1.14 \mathrm{x}+0.33, \mathrm{r}=0.752$.

The confidence belts indicate the range for a single predictive value at $\alpha=0.05$. 
- Simple procedure on standard equipment

- Insensitivity to lipolysis and high free fatty acid concentrations caused by heparin application or ageing of the specimen, at least for the $\alpha$-lipoprotein quantitation

\section{References}

1. Rifkind, B. M. (1984) The Lipid Research Clinics Coronary Primary Prevention Trial Results I. Reduction in incidence of coronary heart disease. Il. The relationship of reduction in incidence of coronary heart disease to cholesterol lowering. J. Am. Med. Ass. 251, 351-374.

2. Assmann, G. \& Schulte, H. (1986) Procam-Trial. In: Procam-Trial (Assmann, G. \& Schulte, H., eds.) Hedingen/ Zuerich: Panscientia-Verlag.

3. Frick, M. H., Elo, O., Haapa, K., Heinonen, O. P., Heinsalmi, P., Helo, P., Huttunen, J. K., Kaitaniemi, P., Koskinen, P., Manninen, V., Mäenpää, H., Mälkönen, M., Mänttäri, M., Norola, S., Pasternack, A., Pikkarainen, J., Romo, M., Sjöblom, T. \& Nikkilä, E. A. (1987) Helsinki Heart Study primary prevention trail with Gemfibrocil in middle aged men with dyslipidaemia. New Engl. J. Med. 317, $1237-1245$

4. Cremer, P., Wieland, H. \& Seidel, D. (1988) Göttinger Risiko-, Inzidenz- und Prävalenzstudie (GRIPS). Aufbau und bisherige Ergebnisse. Münch. Med. Wochenschr. 14, $268-274$.

5. Assmann, G., Schriewer, H., Schmitz, G. \& Haegele, E. O. (1983) Quantification of high-density lipoprotein cholesterol by precipitation with phosphotungstic acid/MgCl . Clin. Chem. 29, 2026-2030.

6. Wieland, H. \& Seidel, D. (1983) A simple specific method for precipitation of low density lipoproteins. J. Lipid Res. 24, 904-909.

7. Draeger, B., Wahlefeld, A. W. \& Ziegenhorn, J. (1982) A practical method for HDL cholesterol quantitation. Lab. Med. 6, 198-202.

8. Assmann, G., Jabs, H. U., Kohnert, U., Nolte, W. \& Schriewer, H. (1984) LDL-cholesterol determination in blood serum following precipitation of LDL with polyvinylsulfate. Clin. Chim. Acta 140, 77-83.

9. Neubeck, W., Wieland, H., Habenicht, A., Mueller, P., Baggio, G. \& Seidel, D. (1977) Improved assessment of plasma lipoprotein patterns. III. Direct measurement of lipoproteins after gel-electrophoresis. Clin. Chem. 23, 1296-1300.

10. Cremer, P., Seidel, D. \& Wieland, H. (1985) Quantitative Lipoproteinelektrophorese: Ihre routinemäßige Anwendung im Vergleich mit anderen Verfahren zur differenzierten Untersuchung des Fettstoffwechsels. Lab. Med. 9, 39-51.

11. Bojanovski, D., Wippermann, B., Molinari, E., Schuster, J. \& Canzler, H. (1981) Accuracy and reproducibility of a quantitative electrophoresis of plasma lipoproteins: interlaboratory comparison and verification by ultracentrifugation. Clin. Chim. Acta 116, 381-387.

12. Wieland, $\mathrm{H}$. (1985) Lipoprotein-Quantifizierung nach elektrophoretischer Trennung: Indikation und Interpretation. Mitteilungen der Dt. Ges. f. Klin. Chemie e. V. 16, 48-57.

13. Wieland, H., Niazi, M., Bartholome, M. \& Seidel, D. (1980) Eine neue Methode zur Messung von Plasmalipoprotein. Ärztl. Lab. 26, 257-266.

14. Wilhelm, K. (1985) Lipoproteindiagnostik im Routinelabor. Krankenhausarzt 58, 444-451.

15. Maerz, W. \& Gross, W. (1986) Analysis of plasma lipoproteins by ultracentrifugation in a new fixed angle rotor: Evaluation of phosphotungstic acid/ $\mathrm{MgCl}_{2}$ precipitation and quantitative lipoprotein electrophoretic assay. Clin. Chim. Acta 160, 3-18.
- Calculation as simple as that for standard protein electrophoresis

- Equally suited for plasma and serum

\section{Acknowledgement}

We wish to thank Ms. U. Weber for her excellent technical assistance.

16. Niedmann, P. D., Luthe, H., Wieland, H., Schaper, G. \& Seidel, D. (1983) Richtigkeit der HDL-Cholesterinmessung. Klin. Wochenschr. $61,133-138$

17. Muecke, H. 1985) Das Verhältnis von Cholesterin zu Protein (Apo B) in Low-Density-Lipoproteinen von Patienten mit und ohne angiographisch gesicherter KHK. Mitteilungen der Dt. Ges. f. Klin. Chemie e. V. 16, 234-239.

18. Eisenberg, S. (1987) Lipoprotein abnormalities in hypertriglyceridemia: Significance in atherosclerosis. Am. Heart. J. $113,555-561$

19. Goldberg, A. C., Schonfeld, G., Anderson, C. \& Dillingham, M. A. (1987) Fenofibrat affects the composition of lipoproteins. Am. J. Med. 27, 60-65.

20. Cobb, S. A. \& Sanders, J. L. (1978) Enzymic determination of cholesterol in serum lipoproteins separated by electrophoresis. Clin. Chem. 24, 1116-1120.

21. Kupke, I. (1979) New principle for the separation of plasma lipoprotein lipids without ultracentrifugation. J. Chromatogr. $162,414-421$.

22. Aufenanger, J., Weber, U., Haux, P. \& Kattermann, R. (1988) A specific method for the direct determination of lipoprotein cholesterol in electrophoretic patterns. Clin. Chim. Acta 177, 197-208.

23. Wieland, H. \& Seidel, D. (1978) Fortschritte in der Analytik des Lipoproteinmusters. Innere Medizin 7, 290-300.

24. Roeschlau, P., Bernt, E. \& Gruber, W. (1974) Enzymatic determination of total cholesterol in serum. J. Clin. Chem. Clin. Biochem. 12, 403.

25. Ziegenhorn, J. (1975) Improved method for enzymatic determination of serum triglycerides. Clin. Chem. 21, 16271629.

26. Passing, H. (1983) A new biometrical procedure for testing the equality of measurements from two different analytical methods. Part I. J. Clin. Chem. Clin. Biochem. 21, 709720.

27. Passing, H. (1984) Comparison of several regression procedures for method comparison studies and determination of sample size. Part II. J. Clin. Chem. Clin. Biochem. 22, $431-445$.

28. Hohenwallner, W., Wimmer, E. \& Sommer, R. (1980) Referenzbereiche der Lipoproteinfraktionen mit Lipidophor. Ärztl. Lab. 11, 293-295.

29. Noble, R. P. (1968) Electrophoretic separation of plasma lipoproteins in agarose gel. J. Lipid Res. 9, 693-700.

30. Friedewald, W. T., Levy, R. J. \& Fredrickson, D. S. (1972) Estimation of the concentration of low-density lipoprotein cholesterol in plasma, without use of the preparative ultracentrifuge. Clin. Chem. 18, 499-502.

31. Breier, Ch., Lisch, H. J., Drexel, H. \& Braunsteiner, H. (1986) Stellenwert der Lipoproteinelektrophorese für die quantitative Bewertung von Plasmalipoproteinen. Dtsch. Med. Wochenschr. 111, 1888-1890.

Dr. Johannes Aufenanger

Institut für Klinische Chemie

Klinikum Mannheim der Universität Heidelberg

Postfach 100023

D-6800 Mannheim 
